\title{
STUDI RUANG AKOMODASI FUNGSI PASAR TRADISIONAL PADA PASAR SANTA, JAKARTA
}

\author{
A Study on Spatial Accommodation for Traditional Market, \\ Case Study: Pasar Santa, Jakarta
}

\author{
Astrid Hapsari Rahardjo, S.T., M.E.Des. ${ }^{1}$ \\ Dipl.-Ing, Firmansyah Bachtiar, S.T. ${ }^{2}$ \\ Reza Rezaie $^{3}$ \\ ${ }^{1}$ Program Studi Arsitektur, Universitas Tanri Abeng \\ Email: astrid.rahardjo@tau.ac.id
}

\begin{abstract}
Abstrak
Pasar Santa telah selesai direvitalisasi pada tahun 2006. Program revitalisasi tersebut mengubah bangunannya dari 32 unit bangunan satu tingkat menjadi satu unit bangunan bertingkat tiga khusus untuk mengakomodasi fungsi utama perdagangan dan jasa. Fungsi pendukung seperti manajemen dan musholla diletakkan pada lantai yang terpisah. Penelitian ini merupakan studi terkait ruang akomodasi fungsi pasar tradisional yang terdapat di Pasar Santa, Jakarta. Variabel penelitian dipilih dari empat ketentuan Pemerintah RI lewat keputusan dari Kementerian Kesehatan dan Perdagangan dan Standar Nasional Indonesia (SNI) no. 8152 tahun 2015. Tujuan penelitian ini adalah untuk mengetahui kesesuaian ruang akomodasi fungsi pasar dan elemennya, seperti dimensi dan material, pada Pasar Santa terhadap ketentuan yang dirujuk terutama pada masa operasionalnya yang masih berlangsung hingga saat penelitian ini dilakukan. Namun sebelumnya dilakukan terlebih dahulu penjabaran dan perbandingan antara kondisi Pasar Santa sebelum dan setelah revitalisasi. Hal ini perlu dilakukan agar dapat diketahui seberapa jauh perkembangan pemfasilitasan ruang akomodasi pasar tradisional di Pasar Santa sejak bergabung di bawah naungan PD Pasar Jaya hingga saat ini.
\end{abstract}

Kata kunci: Pasar Santa, rancangan pasar tradisional, ruang akomodasi pasar

\section{PENDAHULUAN}

Pasar Santa merupakan salah satu pasar tradisional di Jakarta Selatan di bawah pengelolaan PD Pasar Jaya sejak tahun 1971. (PD Pasar Jaya, 2014) Pada tahun 2004, seluruh area Pasar Santa dibongkar untuk direvitalisasi yang kemudian mengubah fasilitas bangunannya yang terdiri dari 32 unit bangunan permanen dan semi-permanen berlantai satu menjadi bangunan bermassa tunggal setinggi tiga lantai termasuk lantai semi-basement ditambah lantai khusus untuk ruang pengelola dan ruang ibadah. Perubahan meliputi antara lain penambahan jumlah ruang dagang berupa kios dan los, toilet dan fasilitas pendukung lain serta penggantian material penutup dengan material yang berbeda dari sebelumnya.

Penelitian ini merupakan studi yang mengamati perubahan yang terjadi pada Pasar Santa sebelum dan setelah revitalisasi dalam aspek ruang pengakomodasian fungsi kegiatan pasar tradisional. Adapun variabel penelitian yang digunakan adalah ruang arsitektural dan elemennya yang disebut di dalam berbagai ketentuan Pemerintah RI terkait akomodasi pasar tradisional. Ruang-ruang yang disebut kemudian diklasifikasikan ruang utama fungsi pasar tradisional dan 
ruang pendukungnya. Metode yang digunakan adalah metode deskriptifkomparatif dengan terlebih dahulu menjabarkan variabel-variabel yang meliputi antara lain zonasi, tipe ruang, material dan ukurannya melalui narasi, ilustrasi dan foto pada saat sebelum dan setelah revitalisasi dilakukan kemudian kedua keadaan tersebut dibandingkan untuk ditemukan perbedaan dan kesamaannya. Kemudian variabel yang diteliti tersebut dicocokkan kesesuaiannya dengan Ketentuan yang dirujuk.

Adapun ketentuan Pemerintah yang digunakan dalam penelitian ini meliputi:

a. Keputusan Menteri Kesehatan RI No. 519/Menkes/SK/IV/2008 mengenai pedoman penyelenggaraan pasar sehat. Secara umum ketentuan ini menyebutkan tentang persyaratan kesehatan di lingkungan pasar dengan penyebutan ruang pengakomodasian pasar tradisional antara lain terkait pembedaan zonasi area perdagangan dan tipe ruang dagang berdasarkan komoditas yang diperjualbelikan, syarat ukuran dan material bidang kerja untuk komoditas minimal setinggi $60 \mathrm{~cm}$ dari permukaan lantai dan penggunaan material yang tahan karat dan tidak terbuat dari kayu, pemisahan zona parkir berdasarkan kegiatan pengguna pasar, penyediaan fasilitas sanitasi berdasarkan jumlah pengguna pasar, ketentuan luasan ruang pengelola, dan penyediaan fasilitas ruang ibadah.

b. Peraturan Menteri Perdagangan RI No. 70/ M-DAG/PER/12/2013 tentang pedoman penataan dan pembinaan pasar tradisional, pusat perbelanjaan dan toko modern. Peraturan ini perbedaan antara ketiga fasilitas perdagangan tersebut dilihat dari luasan dan jenis perizinannya. c. Standar Nasional Indonesia (SNI) tentang Pasar Rakyat no. 8152 tahun 2015. SNI ini mengatur tentang panduan penyelenggaraan sarana dan prasarana pasar tradisional berdasarkan jumlah pedagang dan berbagai subyek yang disebutkan di tabel di bawah ini.

Tabel 1. Klasifikasi tipe pasar berdasarkan SNI no. 8152 tahun 2015

Tipe Pasar Jumlah Pedagang (orang)

\begin{tabular}{cc}
\hline I & $>750$ \\
\hline II & $501-750$ \\
\hline III & $250-500$ \\
\hline IV & $<250$
\end{tabular}

Tabel 2. Beberapa aspek antara lain yang disebutkan dalam SNI no. 8152 tahun 2015

Subyek Panduan

Deskripsi

\begin{tabular}{cc}
\hline $\begin{array}{c}\text { Ukuran ruang } \\
\text { dagang }\end{array}$ & $1-2 \mathrm{~m}^{2}$ \\
\hline Zonasi & $\begin{array}{c}\text { Pangan basah, kering, dan } \\
\text { siap saji, non-pangan }\end{array}$ \\
\hline Parkir & Jumlah yang proporsional \\
\hline Akses kendaraan & Terpisah dari bangunan \\
\hline Lebar koridor & $1,2-1,8 \mathrm{~m}$ \\
\hline Ruang ibadah & Ada \\
\hline Ruang menyusui & Deskripsi \\
\hline Subyek Panduan & Berada pada $2-4$ lokasi \\
\hline Toilet & yang berbeda \\
& 1-4 toilet pria dan wanita \\
\hline Area hijau & Ada \\
\hline Akses difabel & Ada \\
\hline TPS & Ada
\end{tabular}

d. Peraturan Menteri Perdagangan RI No. 37/M-DAG/PER/5/2017 tentang pedoman pembangunan dan pengelolaan sarana perdagangan. Pada poin tentang bangunan pasar tradisional, peraturan ini memberikan gambaran tentang klasifikasi pasar rakyat ditinjau dari banyaknya jumlah pedagang yang diakomodasi dan luasan bangunan pasar tersebut. 
Tabel 3. Klasifikasi Tipe Pasar Berdasarkan Peraturan Terkait

\begin{tabular}{cccc}
$\begin{array}{c}\text { Tipe } \\
\text { Pasar }\end{array}$ & Operasional & $\begin{array}{c}\text { Jumlah } \\
\text { Pedagang } \\
\text { (orang) }\end{array}$ & $\begin{array}{c}\text { Luas } \\
\text { Bangunan } \\
\left(\mathbf{m}^{\mathbf{2}}\right)\end{array}$ \\
\hline A & Harian & 400 & 5.000 \\
\hline B & 3 dari 7 hari & 275 & 4.000 \\
\hline C & 2 dari 7 hari & 200 & 3.000 \\
\hline D & 1 dari 7 hari & 100 & 2.000 \\
\hline Selain & Harian & 2.500 & 6.000
\end{tabular}

$A-D^{*}$

*Catatan: Jenis komoditas tidak terbatas barang kebutuhan sehari-hari, bangunan memiliki nilai sejarah, dan memiliki sumbangan terhadap Produk Domestik Bruto Daerah.

Peraturan ini juga mensyaratkan adanya fasilitas pendukung antara lain kantor pengelola, toilet, ruang peribadatan, tempat parkir, dan tempat penampungan sampah sementara.

Variabel penelitian yang diambil dari berbagai ketentuan yang disebutkan di atas dicantumkan dalam tabel berikut:

Tabel 4. Variabel terpilih pada penelitian ini

\begin{tabular}{|c|c|c|c|c|}
\hline Fungsi Ruang & A & B & C & D \\
\hline \multicolumn{5}{|l|}{ Utama } \\
\hline 1. Zonasi komoditas & $\mathrm{Y}$ & $\mathrm{T}$ & $\mathrm{Y}$ & $\mathrm{Y}$ \\
\hline $\begin{array}{l}\text { 2. Tipe, dimensi dan material ruang } \\
\text { dagang }\end{array}$ & $\mathrm{Y}$ & $\mathrm{Y}$ & $\mathrm{Y}$ & $\mathrm{T}$ \\
\hline 3. Fasilitas penyimpanan/gudang & $\mathrm{T}$ & $\mathrm{T}$ & $\mathrm{Y}$ & $\mathrm{Y}$ \\
\hline $\begin{array}{l}\text { 4. Tempat pembuangan sampah } \\
\text { sementara (TPS) }\end{array}$ & $\mathrm{Y}$ & $\mathrm{T}$ & $\mathrm{Y}$ & $\mathrm{Y}$ \\
\hline \multicolumn{5}{|l|}{ Pendukung } \\
\hline $\begin{array}{l}\text { 1. Akses dan parkir kendaraan } \\
\text { bermotor }\end{array}$ & $\mathrm{Y}$ & $\mathrm{T}$ & $\mathrm{Y}$ & $\mathrm{Y}$ \\
\hline $\begin{array}{l}\text { 2. Sirkulasi diantara ruang dagang } \\
\text { (kios atau los) }\end{array}$ & $\mathrm{Y}$ & $\mathrm{T}$ & $\mathrm{Y}$ & $\mathrm{T}$ \\
\hline $\begin{array}{l}\text { 3. Ruang pengelola, ruang ibadah, } \\
\text { ruang menyusui, toilet }\end{array}$ & $Y$ & $\mathrm{~T}$ & $Y$ & $\mathrm{Y}$ \\
\hline
\end{tabular}

A Keputusan Menteri Kesehatan RI No. 519/Menkes/SK/IV/2008

B Peraturan Menteri Perdagangan RI No. 70/ MDAG/PER/12/2013

C Standar Nasional Indonesia (SNI) tentang Pasar Rakyat no. 8152 tahun 2015

D Peraturan Menteri Perdagangan RI No. 37/MDAG/PER/5/2017

Penelitian ini bertujuan untuk mengetahui ruang pengakomodasian pasar tradisional serta kondisinya secara umum yang terdapat di Pasar Santa sebelum revitalisasi, perubahan yang terdapat pada Pasar Santa setelah revitalisasi dilaksanakan serta pemenuhan persyaratan dari berbagai ketentuan Pemerintah RI pada masa operasionalnya dari tahun 2006 hingga saat penelitian ini dilakukan.

\section{PEMBAHASAN}

\section{Pasar Santa Sebelum Revitalisasi}

Pada saat Pasar Santa masuk ke dalam naungan PD. Pasar Jaya di tahun 1971, wilayah Pasar Santa dikelilingi oleh jalan lingkungan setempat. Luas tapak saat itu adalah $6.240 \mathrm{~m}^{2}$ dengan fasilitasnya berupa bangunan permanen dan semipermanen satu lantai seluas $1.800 \mathrm{~m} 2$ dan area parkir. Pengembangan Pasar Santa kemudian dilakukan secara bertahap dengan pelebaran tapak hingga menutup sebagian jalan di sisi timur dan baratnya serta menutup seluruh jalan di sisi selatannya dan dengan menambah unit bangunan. Pada tahun 1991, luas total tapak dan bangunan mencapai $8.010 \mathrm{~m}^{2}$ dan $3.100 \mathrm{~m}^{2}$ (38.7\% dari luas tapak) yang meliputi 21 unit bangunan permanen dan 11 unit semi-permanen setinggi satu lantai. Ruang terbuka pada tapak digunakan untuk sirkulasi dan parkir kendaraan, tempat pembuangan sampah sementara, dan sebagai tempat berjualan makanan pada malam hari. (Rahardjo, 2005)

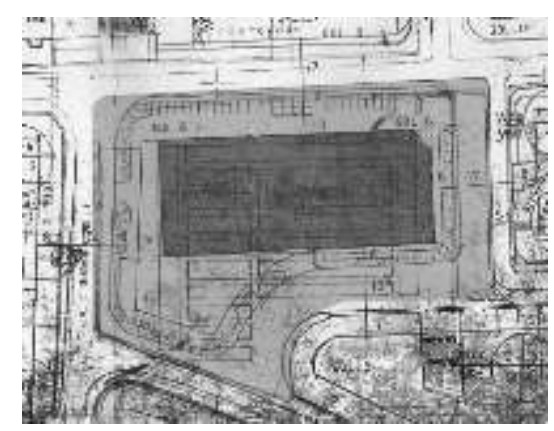

Gambar 1. Peta peruntukan Pasar Santa di tahun 1971 dan area Pasar Santa terakhir (dalam arsiran abu-abu). (Sumber: Rahardjo, 2005) 


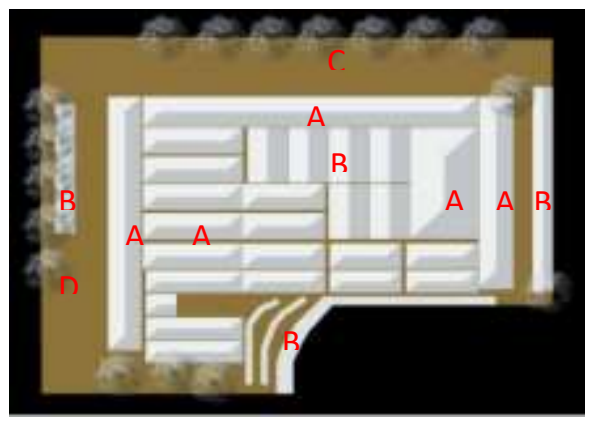

Gambar 2. Ilustrasi tiga dimensi Pasar Santa pada tahun 2004 sebelum dilakukan revitalisasi. (Sumber: Rahardjo, 2005)

Tabel 5. Keterangan tipe bangunan dan fungsi yang diakomodasi pada Pasar Santa sebelum revitalisasi

\begin{tabular}{cl}
$\begin{array}{c}\text { Tipe } \\
\text { Bangunan }\end{array}$ & \multicolumn{1}{c}{ Fungsi yang Diakomodasi } \\
\hline A & Bangunan permanen; \\
\hline B1 & $\begin{array}{l}\text { Bangunan semi-permanen di tengah- } \\
\text { tengah pasar }\end{array}$ \\
\hline B2 & Bangunan semi-permanen di pinggir pasar \\
\hline C & Zona alih-fungsi \\
\hline D & $\begin{array}{l}\text { Tempat pembuangan sampah sementara } \\
\text { (TPS) }\end{array}$
\end{tabular}

A. Ruang Akomodasi Fungsi Utama

1. Zonasi Komoditas Perdagangan dan Jasa Pemisahan komoditas perdagangan dan jasa di Pasar Santa sebelum revitalisasi tidak terlihat signifikan selain daripada adanya penempatan komoditas bahan makanan basah secara mayoritas pada unit bangunan semi-permanen di sisi tengah dan selatan tapak. Namun sebagian dari tempat berdagang di area tersebut juga ditempati oleh komoditas non-makanan dan makanan kering.

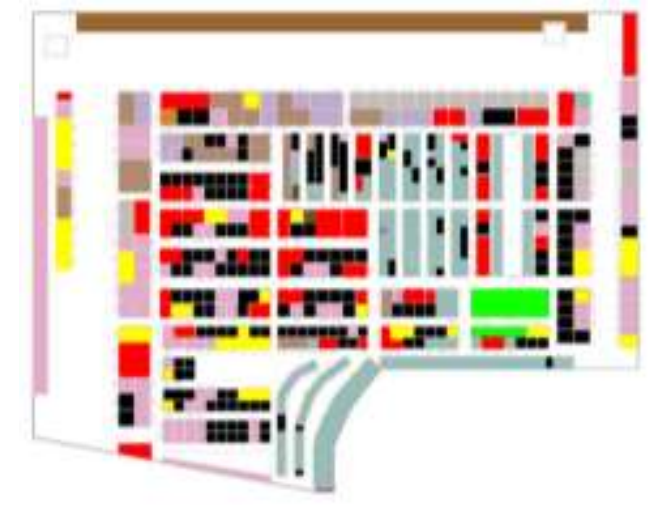

Gambar 3. Zona komoditas di Pasar Santa (Sumber: Rahardjo, 2005)
Ruang pada bangunan permanen dan semi-permanen lainnya digunakan untuk mengakomodasi unit dagang dan jasa secara bervariasi, mulai dari bahan makanan, makanan jadi, pakaian, dan berbagai kebutuhan lainnya.

Tabel 6. Keterangan penempatan komoditas pada Pasar Santa sebelum revitalisasi

\begin{tabular}{ll} 
Warna & \multicolumn{1}{c}{ Zona } \\
\hline & Pangan basah, hasil tani dan unggas \\
\hline & Pangan kering dan makanan jadi \\
\hline Jasa (penjahitan dan bengkel) \\
\hline Peralatan rumah tangga \\
\hline Keperluan pribadi dan keluarga \\
\hline Material bangunan \\
\hline Kosong dan sebagai gudang \\
\hline Fasilitas publik dan kantor pengelola \\
\hline Herbal tradisional dan pangan hewan \\
\hline Zona alih-fungsi
\end{tabular}

2. Tipe, Dimensi dan Material Ruang Dagang

Sebelum Pasar Santa direvitalisasi terdapat dua tipe bangunan untuk mengakomodasi fungsi kegiatan pasar tradisional, yaitu bangunan permanen dan semi-permanen. Bangunan permanen pun terbagi dua yaitu bangunan permanen yang menaungi los dagang khusus untuk penjualan daging dan bangunan permanen yang grid strukturnya mendikte pembagian ruang dagang. Pada bangunan los daging, tiap los dibuat terbuka dengan material dinding yang terbuat dari batu bata dan plesteran dan material meja dagang yang terbuat dari beton bertulang. Adapun material penutup yang digunakan berupa keramik berwarna putih berukuran $20 \times 20 \mathrm{~cm}$. Pada bangunan permanen yang lainnya tiap kios dapat dibatasi dinding dengan material batu bata dengan plesteran dan acian beton atau papan kayu. Tiap unit kios memiliki dimensi $3 \times 3 \mathrm{~m}$ yang dihasilkan oleh jarak kolom strukturnya. Tiap kios dapat ditutup dengan papan 
atau pintu lipat kayu pada saat pasar tidak beroperasi. Tiap kios juga dilengkapi dengan ventilasi berupa jalusi di atas bukaan.
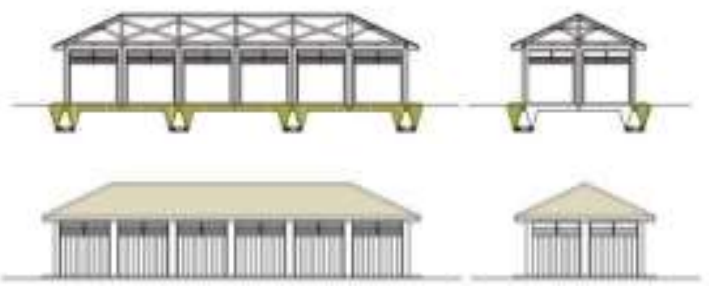

Gambar 4. Ilustrasi bangunan permanen (Sumber: Rahardjo, 2005)

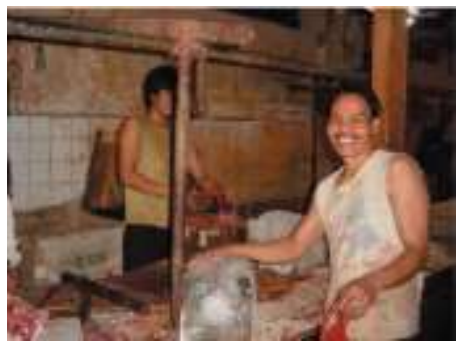

Gambar 5. Contoh los daging pada bangunan permanen (Sumber: Rahardjo, 2005)

Pada bangunan semi-permanen tiap ruang dagang dibuat sebagai los terbuka dengan dimensi $2 \times 2 \mathrm{~m}$ dan dengan menggunakan struktur pipa baja. Tiap pedagang menggunakan meja kayu yang dilapisi oleh penutup dengan bahan dasar plastik sebagai pelapisnya.
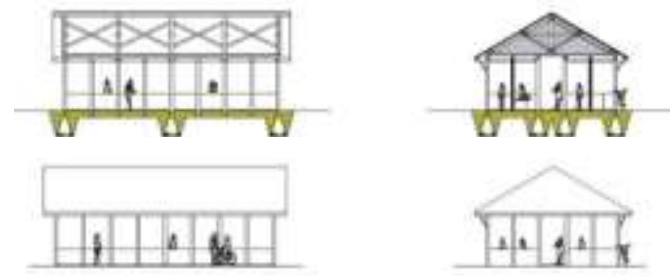

Gambar 6. Ilustrasi bangunan semi-permanen berupa los terbuka (Sumber: Rahardjo, 2005)

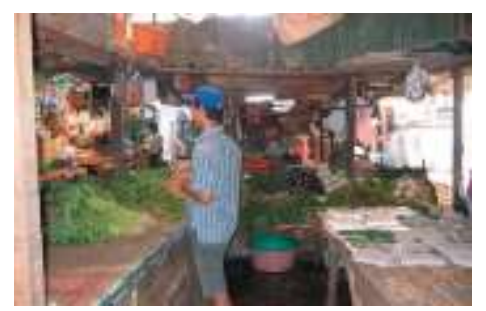

Gambar 7. Contoh penggunaan los terbuka di bangunan semi-permanen
3. Fasilitas Penyimpanan atau Gudang

Pihak pengelola Pasar Santa tidak menyediakan ruang khusus untuk penyimpanan barang bagi para pedagang dan penyedia jasa. Hal tersebut menyebabkan adanya penggunaan ruang dagang atau kios dan los yang tidak digunakan sebagai gudang. Pada bangunan semipermanen, penggunaan ruang terbuka sebagai gudang memberikan kesan penumpukan barang pada los namun penerapan fungsi gudang pada bangunan permanen membuat kios tersebut ditutup rapat dan dikunci. Sebagai akibatnya, tidak terdapat perbedaan secara visual yang jelas antara kios yang non-aktif dengan kios yang digunakan sebagai gudang. Hal ini menjadikan area di sekitarnya menjadi sepi sehingga berpotensi untuk menimbulkan masalah keamanan.

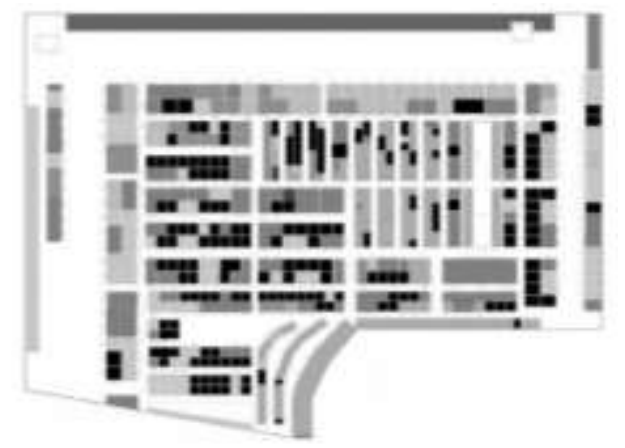

Gambar 8. Posisi ruang yang digunakan sebagai gudang atau ruang yang non-aktif dapat dilihat pada posisi yang ditandai dengan warna hitam (Sumber: Rahardjo, 2005)

4. Tempat pembuangan sampah sementara (TPS)

Fasilitas pembuangan sampah di Pasar Santa pada saat ini berupa sistem pembuangan terpusat. Fasilitas ini dibatasi dengan dinding dengan ukuran area kurang lebihnya $8 \times 8 \times 2 \mathrm{~m}$. Akses menuju tempat pembuangan sampah sementara dapat dimasuki melalui sisi selatan tapak, yakni lewat Jalan Cisanggiri V. 


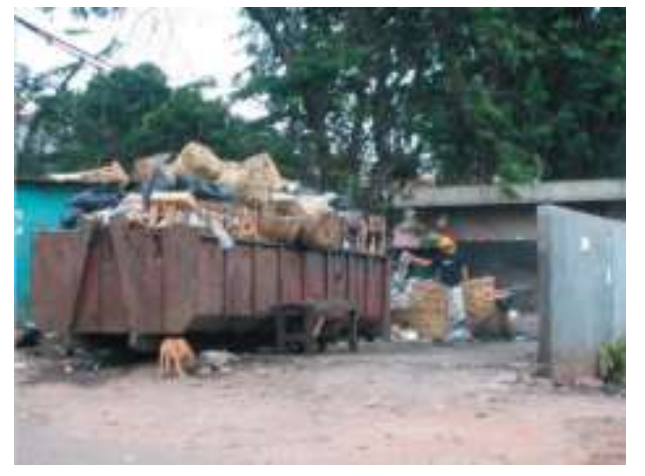

Gambar 8. Tempat pembuangan sampah sementara (Sumber: Rahardjo, 2005)

B. Ruang Akomodasi Fungsi Pendukung

1. Akses dan parkir kendaraan bermotor

Pasar Santa dapat diakses dengan kendaraan bermotor lewat bukaan tapak di keempat pojokan tapak sedangkan akses khusus pejalan kaki dapat ditemui di sisi utara dan selatan tapak. Pemisahan jenis parkir kendaraan untuk pengguna dan bongkar muat tidak ditemukan secara jelas namun parkir untuk kendaraan bermotor umumnya disediakan di sisi utara tapak sedangkan parkir untuk bongkar muat umumnya dapat ditemukan pada sisi timur dan barat tapak. Dikarenakan tidak ada kejelasan jalur masuk dan keluar sering terjadi masalah alur kendaraan di dalam tapak.

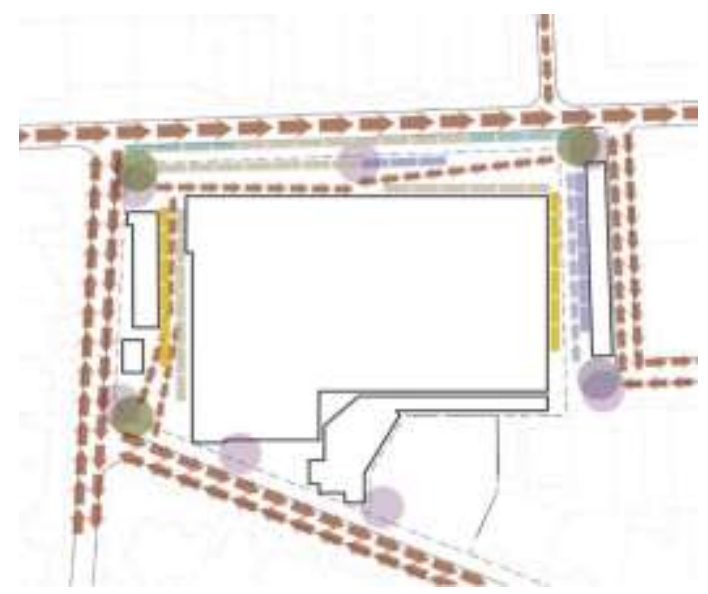

Gambar 9. Diagram akses masuk, sirkulasi dan parkir berbagai kendaraan bermotor yang tidak memiliki keteraturan dan pemisahan.

(Sumber: Rahardjo, 2005)
2. Sirkulasi Pada Bangunan Pasar

Lebar ruang sirkulasi di antara ruang dagang dan bangunan umumnya sekitar 1,5-1,8 m. Namun di beberapa area, ruang sirkulasi ini digunakan untuk menaruh komoditas dagangan sehingga membuat ruang gerak menjadi sempit.

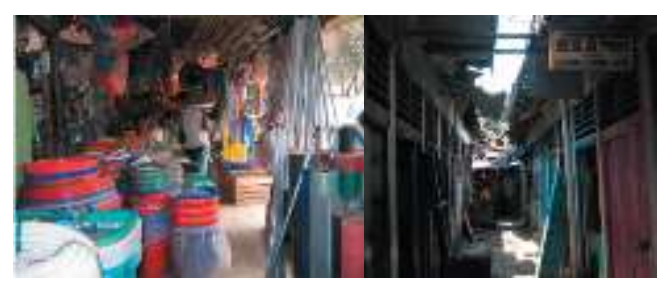

Gambar 10A dan B. Sirkulasi pada depan kios yang dipenuhi dengan komoditas dagangan hingga menyisakan ruang gerak yang relatif sempit. (Sumber: Rahardjo, 2005)

3. Ruang Pengelola, Ibadah, dan Toilet Sebelum revitalisasi, ruang ibadah berupa musholla dan toilet yang merupakan juga kamar mandi bagi pedagang dan pekerja Pasar Santa terletak di satu bangunan di sisi selatan bangunan los daging sedangkan ruang pengelola berada di bangunan terpisah namun berdekatan dengan musholla dan toilet tersebut.

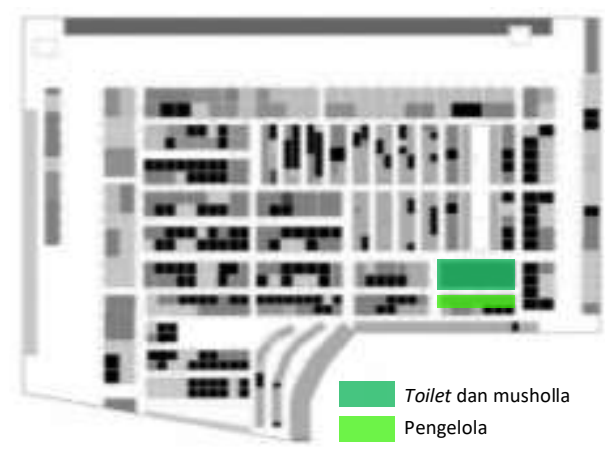

Gambar 11. Posisi ruang pendukung berupa ruang pengelola, ruang ibadah dan kamar mandi (Sumber: Rahardjo, 2005)

\section{Pasar Santa Setelah Revitalisasi}

Program revitalisasi yang dilaksanakan di mengubah fisik fasilitas Pasar Santa dari bangunan majemuk satu lantai menjadi bangunan tunggal dengan 3 lantai 
ditambah dengan satu lantai semibasement. Dengan luasan tapak yang sama, luasan total bangunan menjadi sekitar $8.700 \mathrm{~m} 2$ atau $280 \%$ lebih luas dari sebelum revitalisasi sehingga otomatis dapat mengakomodasi lebih banyak ruang dagang berupa kios dan los. Adapun material konstruksi bangunan yang digunakan pada bangunan ini umumnya berupa beton bertulang untuk strukturnya yang dipadu dengan baja untuk struktur atap bentang lebar, bata ringan dan plesteran serta acian dari beton untuk dindingnya kecuali pada area los terbuka yang diberikan penutup dinding dari keramik yang berukuran $20 \times 20 \mathrm{~cm}$. Adapun material penutup lantai yang digunakan berupa keramik dengan warna dan ukuran yang bervariasi.

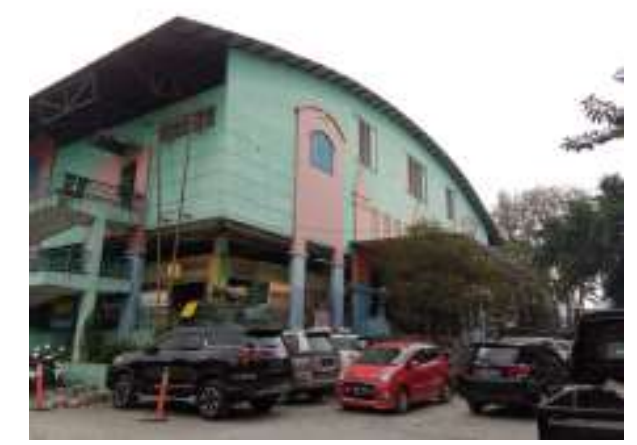

Gambar 12. Pasar Santa setelah direvitalisasi (Sumber: dokumentasi tim peneliti)

\section{A. Ruang Akomodasi Fungsi Utama}

1. Zonasi Komoditas Perdagangan dan Jasa Upaya untuk membedakan zona ruang berdasarkan komoditas pada Pasar Santa terlihat relatif lebih jelas daripada sebelumnya.

Pada lantai semi-basement, penjualan bahan makanan basah seperti sayur dan daging ditempatkan area los terbuka yang ditandai dengan warna biru. Zona yang ditandai dengan warna merah memperlihatkan area yang diisi oleh pedagang bahan makanan kering dan alat kebutuhan rumah tangga yang bercampur dengan penyedia jasa seperti penjahitan dan kurir.

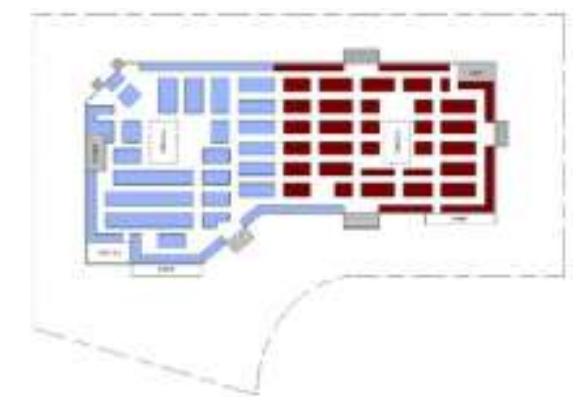

Gambar 13. Pembagian zonasi di lantai semibasement(Sumber: dokumentasi tim peneliti, 2020)

Pada lantai mezzannine, kios ditempati oleh unit-unit usaha dagang kebutuhan rumah tangga, kebutuhan kantor, jasa bank, jasa kurir, dan penjahitan pakaian dengan posisi yang acak atau tidak teratur. Di lantai ini juga terdapat anjungan tunai mandiri bagi pengguna Pasar Santa

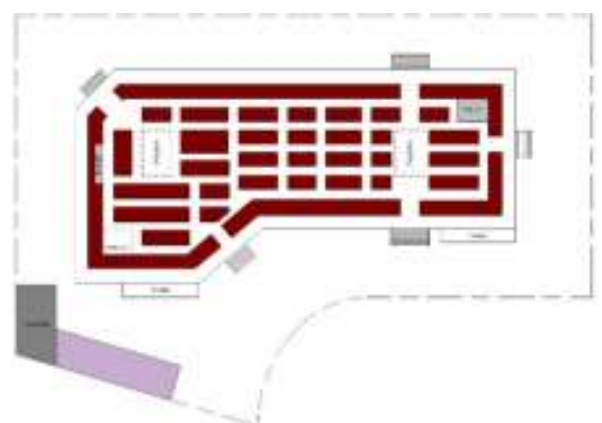

Gambar 14. Pembagian zonasi di lantai semibasement(Sumber: dokumentasi tim peneliti, 2020)

Pada lantai atas, mayoritas unit kios diisi oleh unit usaha mikro, kecil, menengah atau UMKM dengan komoditas yang beragam antara lain dekorasi rumah, barang koleksi zaman dahulu, alat musik, makanan siap saji, dan kudapan. Sebagian lainnya diisi oleh unit usaha makanan yang juga disertai oleh area makan atau food court bagi para pengunjung Pasar Santa. 


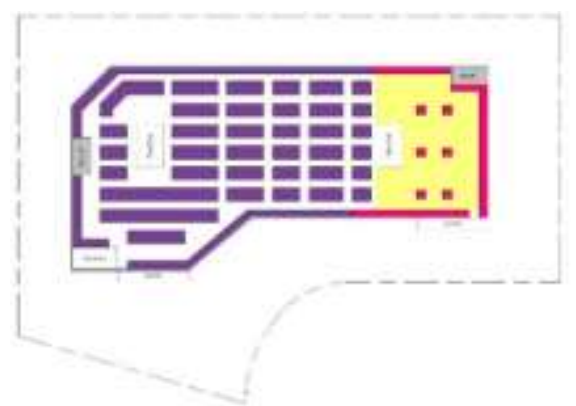

Gambar 15. Zonasi lantai atas yang mayoritas ditempati oleh unit usaha mikro, kecil, menengan (UMKM) dengan komoditas yang beragam dan unit usaha makanan dalam bentuk food court. (Sumber: ilustrasi tim peneliti, 2021)

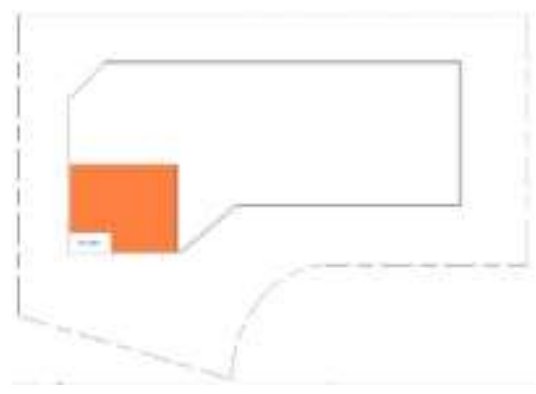

Gambar 16. Zonasi tingkat sejajar atap yang diisi oleh fungsi pendukung berupa musholla dan ruang pengelola Pasar Santa (Sumber: ilustrasi tim peneliti, 2021)

Beberapa fungsi pendukung Pasar ditempatkan pada area yang terletak di tingkat yang sejajar dengan atap. Fungsi tersebut adalah ruang peribadatan berupa musholla dan kantor pengelola.

2. Tipe, Dimensi dan Material Ruang Dagang Seperti halnya sebelum revitalisasi, Pasar Santa memiliki dua tipe ruang dagang yaitu kios dan los terbuka. Namun setelah revitalisasi, setiap unit kios dapat ditutup dengan rolling door yang terbuat dari baja. Setiap kios diberikan kebebasan untuk menambah upaya pembatasan lebih lanjut berupa dinding dan pintu kaca sesuai dengan kebutuhan masing-masing usaha.

Pasar Santa memiliki tiga tipe kios dengan ukuran $2 \times 2 \mathrm{~m}, 2 \times 1,5 \mathrm{~m}$, dan 1,5 $x 1,5 \mathrm{~m}$. Adapun untuk ukuran los hanya terdapat satu tipe ukuran yaitu 1,5 x $1 \mathrm{~m}$. Dalam hal material bangunan lantai yang digunakan pada tiap tingkatnya, terdapat keramik dengan ukuran yang bervariasi yakni $20 \times 20 \mathrm{~cm}, 30 \times 40 \mathrm{~cm}$, dan $40 \times 40$ $\mathrm{cm}$ pada area yang berbeda-beda. Tiap unit kios dan los ditandai areanya dengan lantai keramik yang memiliki ukuran dan warna yang berbeda, yaitu keramik putih berukuran $30 \times 30 \mathrm{~cm}$ untuk area kios dan keramik hijau berukuran $40 \times 40 \mathrm{~cm}$ untuk pembatas tiap kios dan area persimpangan sirkulasi. Adapun ukuran keramik yang digunakan untuk area sirkulasi adalah $40 \times 40 \mathrm{~cm}$.

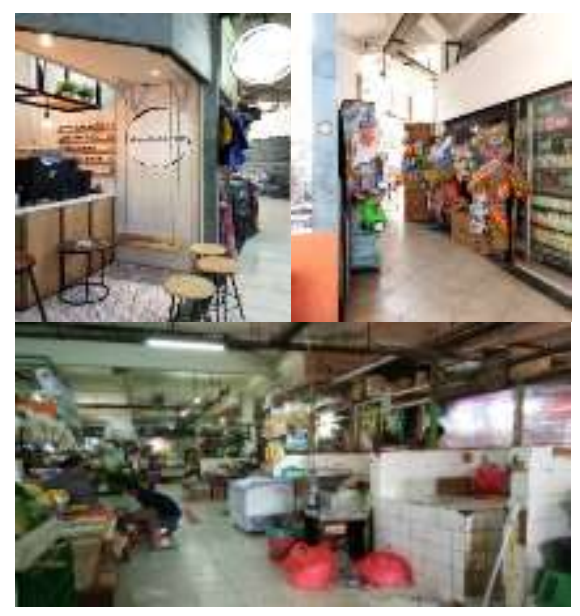

Gambar 17. Material bangunan yang digunakan pada kios dan los (Sumber: dokumentasi tim peneliti, 2020)

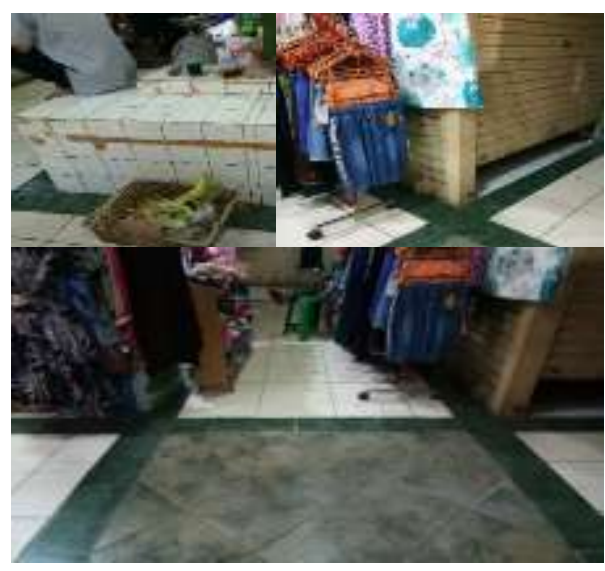

Gambar 18. Tipe dan ukuran keramik penutup lantai yang berbeda-beda (Sumber: dokumentasi tim peneliti, 2020)

Setiap los dilengkapi dengan meja kerja khusus yang terbuat dari beton dan 
diberikan material penutup berupa keramik $20 \times 20 \mathrm{~cm}$ berwarna putih yang relatif mudah untuk dibersihkan. Tinggi bidang kerja pada los adalah $80 \mathrm{~cm}$ dari permukaan lantai. Area los ini juga dilengkapi dengan jalur air seperti parit kecil untuk memudahkan upaya pembersihan los yang disebabkan oleh komoditas bahan makanan basah.

\section{Fasilitas Gudang}

Seperti halnya ketika revitalisasi belum dilakukan, saat ini Pasar Santa juga tidak menyediakan fasilitas gudang bagi pedagang dan penyedia jasa sehingga permasalahan terkait kios dan los yang memberikan tutup atau operasi. Hal ini mengakibatkan kondisi yang sepi pada area sekitar kios dan los tersebut.

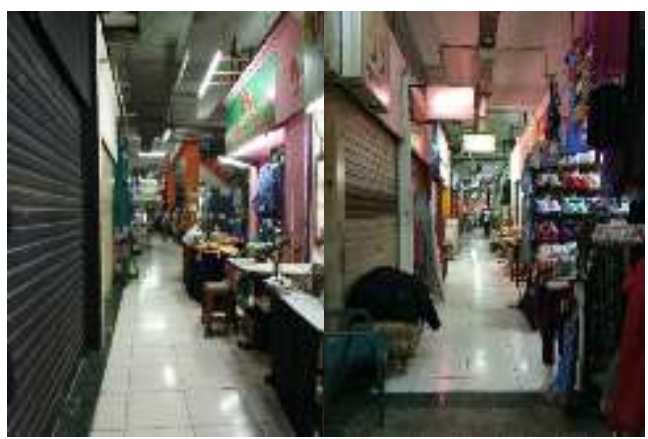

Gambar 19. Koridor di area kios tertutup yang berpotensi digunakan sebagai gudang (Sumber: ilustrasi tim peneliti, 2021)

4. Tempat pembuangan sampah sementara (TPS)

Posisi tempat pembuangan sampah sementara (TPS) tidak dipindahkan dari saat revitalisasi belum dilakukan, yakni pada pojok persimpangan jalan antara sisi barat dan selatan tapak. Namun setelah revitalisasi terdapat pembatasan fisik yang lebih jelas dari sebelumnya yang dilakukan tidak hanya dengan mendirikan dinding setinggi minimal $2 \mathrm{~m}$, namun juga dengan penanaman pohon yang cukup tinggi untuk menekankan pembatasan tersebut serta dengan penutupan area sekitarnya dari akses kendaraan umum ke dalam Pasar.

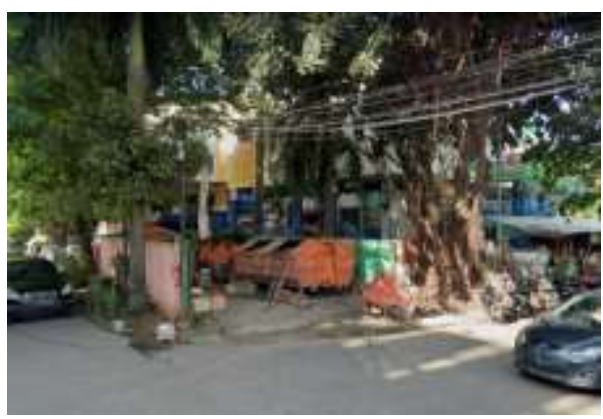

Gambar 20. Tempat pembuangan sampah sementara (TPS) pada Pasar Santa (Sumber: dokumentasi tim peneliti, 2020)

B. Ruang Akomodasi Fungsi Pendukung

1. Akses dan parkir kendaraan bermotor Akses masuk dan keluar Pasar Santa kini lebih dibatasi agar lebih teratur. Akses khusus pejalan kaki, disediakan pada sisi utara Pasar walau pejalan kaki dapat juga keluar dan masuk area Pasar lewat pintupintu kendaraan bermotor. Untuk kendaraan bermotor akses masuk dapat ditemukan pada pojok persimpangan di sisi timur dan barat. Akses keluar khusus untuk mobil diletakkan di sisi selatan, sedangkan untuk motor diletakkan di sisi barat yang berdekatan dengan area parkir motor. Alur sirkulasi kendaraan kini lebih teratur walau dalam hal parkir belum ada pemisahan yang jelas antara parkir untuk kendaraan bongkar-muat dan parkir untuk mobil pengunjung.

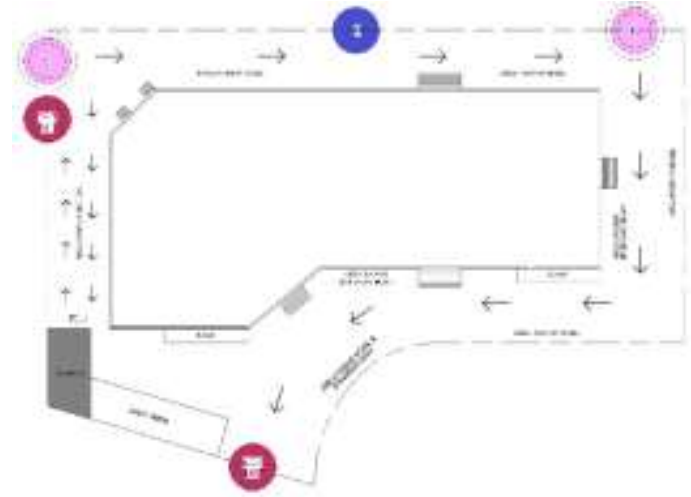

Gambar 21. Ilustrasi titik-titik masuk dan keluar tapak Pasar Santa saat ini (Sumber: ilustrasi tim peneliti, 2021) 
2. Sirkulasi pada bangunan Pasar

Sirkulasi pada bangunan Pasar meliputi area di pinggir dan di dalam bangunan pasar. Sirkulasi pada area di pinggir bangunan meliputi selasar terbuka di lantai mezzannine dengan lebar $1,8 \mathrm{~m}$, ramp dengan lebar $1,2 \mathrm{~m}$ yang terletak pada sisi selatan bangunan dan berdekatan dengan parkir bongkar-muat untuk memudahkan distribusi barang pada tiap tingkat bangunan, dan tangga dengan lebar $8-10 \mathrm{~m}$ di sisi yang berbeda untuk pencapaian tingkat mezzannine dan semi-basement dari luar bangunan. Sirkulasi di dalam bangunan diwujudkan dalam bentuk koridor di antara barisan kios dan barisan los dengan lebar $1,8 \mathrm{~m}$ sedangkan untuk pencapaian tiap tingkat bangunan diwujudkan dalam bentuk tangga dengan lebar yang berbeda di tiap tangga antara 1,8-4 m. Pada bangunan Pasar Santa ini terdapat tiga buah tangga, di mana dua buah tangga terletak relatif di tengah bangunan dan satu buah tangga terletak di sudut selatan bangunan. Tangga ini juga merupakan akses untuk ke musholla dan kantor pengelola.

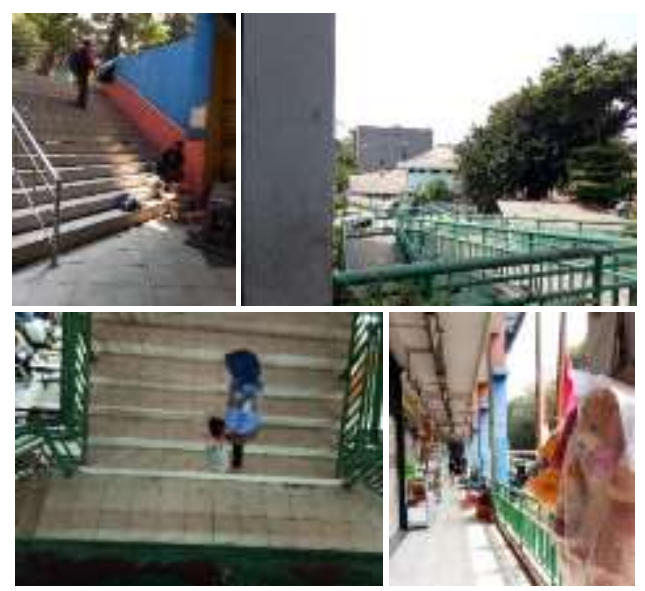

Gambar 22A-D. Sirkulasi berupa tangga, koridor dan ramp yang terdapat di Pasar Santa. (Sumber: Dokumentasi tim peneliti, 2020)

3. Ruang Pengelola, Ibadah dan Toilet Ruang pengelola dan ruang untuk ibadah dalam bentuk musholla ini disediakan di lantai paling atas gedung Pasar Santa. Area ini hanya dapat dicapai melalui tangga yang ada di sisi selatan bangunan.

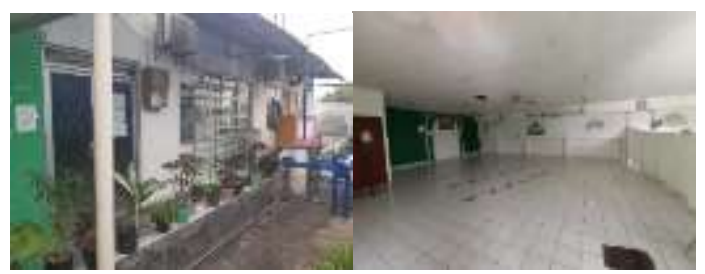

Gambar 123. Tampak depan dari kantor pengelola dan suasana di dalam musholla (Sumber: dokumentasi tim peneliti, 2020)

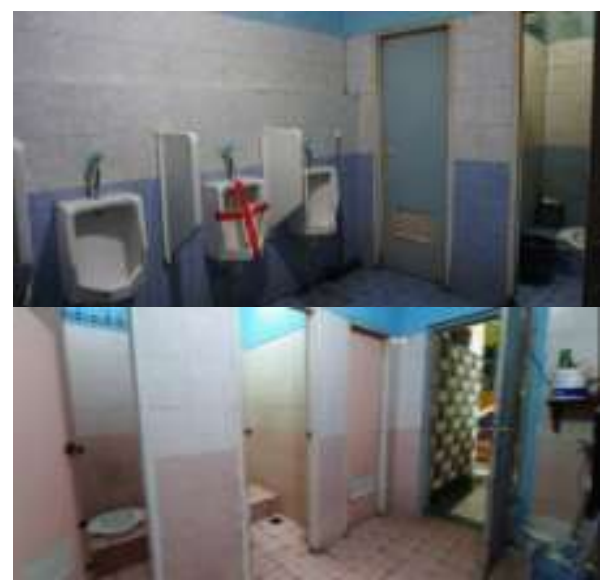

Gambar 24. Toilet pria dan toilet wanita di Pasar Santa (Sumber: dokumentasi tim peneliti, 2020)

Toilet disediakan di tiap lantai pada sisi timur dan barat bangunan dengan jumlah yang lebih memadai daripada sebelum revitalisasi. Adapun untuk informasi detailnya dapat dilihat pada tabel berikut ini:

Tabel 7. Jumlah fasilitas sanitasi di Pasar Santa

\begin{tabular}{lccccccc}
\hline \multicolumn{1}{c}{ Lantai } & \multicolumn{3}{c}{ Toilet Pria } & \multicolumn{4}{c}{ Toilet Wanita } \\
\hline & $\mathrm{W}$ & $\mathrm{U}$ & $\mathrm{W}$ & $\mathrm{K}$ & $\mathrm{W}$ & $\mathrm{W}$ & $\mathrm{K}$ \\
& & & $\mathrm{C}$ & $\mathrm{M}$ & & $\mathrm{C}$ & $\mathrm{M}$ \\
\hline $\begin{array}{l}\text { Semi- } \\
\text { basement }\end{array}$ & 4 & 8 & 2 & 2 & 4 & 4 & 2 \\
\hline Mezzannine & 4 & 8 & 2 & 2 & 4 & 4 & 2 \\
\hline Atas & 4 & 8 & 2 & 2 & 4 & 4 & 2 \\
\hline Total & 12 & 24 & 6 & 6 & 12 & 12 & 6 \\
\hline $\begin{array}{l}\text { Total per sisi } \\
\text { bangunan }\end{array}$ & 6 & 12 & 3 & 3 & 6 & 6 & 3 \\
\hline
\end{tabular}


Perbandingan Ruang Akomodasi Pasar Tradisional pada Pasar Santa Sebelum dan Setelah Revitalisasi

Dari penjabaran terhadap eksistensi dan kondisi ruang pengakomodasian fungsi pasar tradisional pada Pasar Santa sebelum dan setelah revitalisasi ditemukan perbedaan dan persamaannya terkait dengan variabel yang digunakan yang dirinci dalam tabel berikut ini:

Tabel 8. Perbandingan Pengakomodasian Fungsi Pasar Santa Sebelum dan Setelah Revitalisasi

\begin{tabular}{|c|c|c|}
\hline \multirow[t]{2}{*}{$\begin{array}{l}\text { Fungsi } \\
\text { Ruang }\end{array}$} & \multicolumn{2}{|c|}{$\begin{array}{l}\text { Revitalisasi } \\
\text { Pasar Santa }\end{array}$} \\
\hline & Sebelum & Setelah \\
\hline \multicolumn{3}{|l|}{ Utama } \\
\hline $\begin{array}{l}\text { Zonasi } \\
\text { komoditas }\end{array}$ & $\begin{array}{l}\text { Tidak terdapat } \\
\text { perbedaan yang jelas }\end{array}$ & $\begin{array}{l}\text { Perbedaan relatif } \\
\text { lebih jelas }\end{array}$ \\
\hline $\begin{array}{l}\text { Tipe, } \\
\text { dimensi } \\
\text { dan } \\
\text { material } \\
\text { ruang } \\
\text { dagang }\end{array}$ & $\begin{array}{l}1 \text { tipe kios } \\
1 \text { tipe los } \\
\text { Material penutup tidak } \\
\text { seragam } \\
\text { Material tampak rusak }\end{array}$ & $\begin{array}{l}3 \text { tipe kios } \\
1 \text { tipe los } \\
\text { Material penutup } \\
\text { seragam berupa } \\
\text { keramik }\end{array}$ \\
\hline $\begin{array}{l}\text { Fasilitas } \\
\text { gudang }\end{array}$ & $\begin{array}{l}\text { Tidak terdapat gudang } \\
\text { khusus }\end{array}$ & $\begin{array}{l}\text { Tidak terdapat } \\
\text { gudang khusus }\end{array}$ \\
\hline $\begin{array}{l}\text { Tempat } \\
\text { pembuanga } \\
\text { n sampah } \\
\text { sementara } \\
\text { (TPS) }\end{array}$ & $\begin{array}{l}\text { Terdapat TPS di sudut } \\
\text { selatan dan barat } \\
\text { tapak } \\
\text { Pembatasan area } \\
\text { berupa dinding }\end{array}$ & $\begin{array}{l}\text { Terdapat TPS di } \\
\text { sudut selatan dan } \\
\text { barat tapak } \\
\text { Pembatasan lebih } \\
\text { jelas berupa } \\
\text { dinding, } \\
\text { pepohonan dan } \\
\text { penutupan akses di } \\
\text { sekitar TPS }\end{array}$ \\
\hline
\end{tabular}

\begin{tabular}{|c|c|c|}
\hline \multicolumn{3}{|l|}{ Pendukung } \\
\hline \multirow{3}{*}{$\begin{array}{l}\text { Akses dan } \\
\text { parkir } \\
\text { kendaraan } \\
\text { bermotor }\end{array}$} & $\begin{array}{l}\text { Pasar dapat diakses } \\
\text { dari setiap sudut pasar }\end{array}$ & $\begin{array}{l}\text { Pasar dapat } \\
\text { diakses dari setiap } \\
\text { sudut pasar }\end{array}$ \\
\hline & $\begin{array}{l}\text { antara pintu masuk } \\
\text { dan keluar }\end{array}$ & $\begin{array}{l}\text { Pintu masuk dan } \\
\text { keluar dibedakan }\end{array}$ \\
\hline & $\begin{array}{l}\text { Tidak ada pembeda } \\
\text { area parkir tiap jenis } \\
\text { kendaraan }\end{array}$ & $\begin{array}{l}\text { Perbedaan area } \\
\text { parkir untuk mobil, } \\
\text { motor dan } \\
\text { kendaraan } \\
\text { bongkar-muat } \\
\text { relatif lebih jelas }\end{array}$ \\
\hline
\end{tabular}

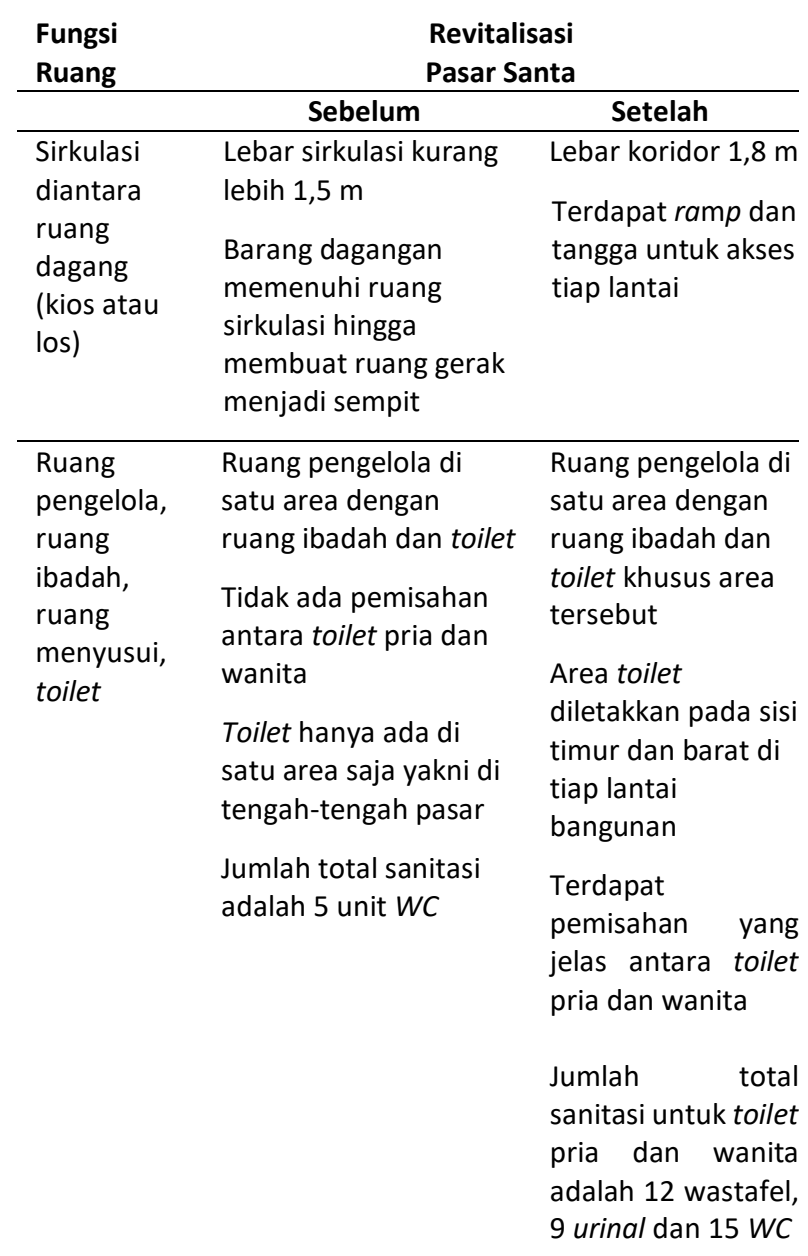

\section{Kesesuaian Pasar Santa dengan Ketentuan Pemerintah RI}

Revitalisasi di Pasar Santa telah selesai dilaksanakan pada tahun 2006. Namun demikian, masa operasional dari fasilitas yang dibangun terus berjalan sampai saat ini. Pada saat penelitian ini dilakukan, Pasar Santa telah mengalami berbagai penyesuaian antara lain terkait pergantian komoditas perdagangan yang menempati kios yang disediakan. Adapun tinjauan terkait ketentuan Pemerintah RI tentang fasilitas pasar tradisional terhadap Pasar Santa terus dikaji baik yang berhubungan langsung terhadap fasilitas yang ada maupun terhadap persyaratan ruang yang belum terpenuhi. 
Tabel 9. Kesesuaian Ruang Akomodasi pada Pasar Santa terhadap Ketentuan Pemerintah RI

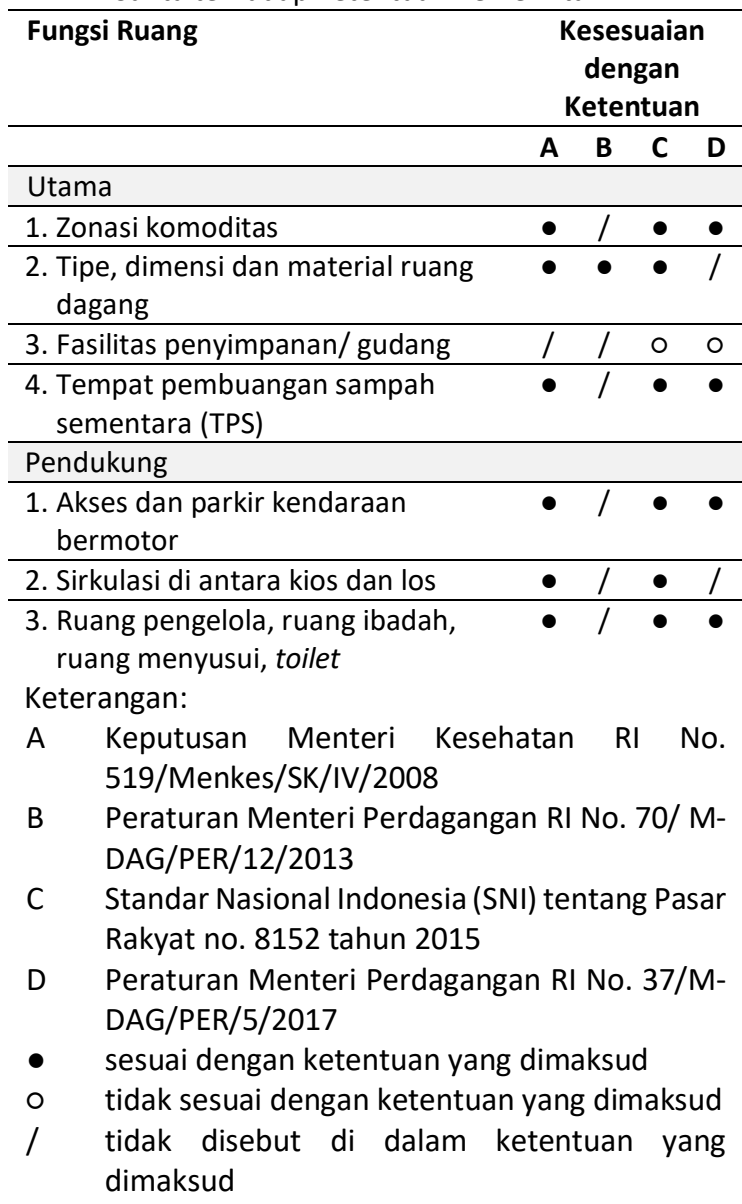

Setelah direvitalisasi, pemisahan zona perdagangan berdasarkan komoditasnya telah terpenuhi terkait dengan karakteristik basah atau keringnya, misalnya perletakan kegiatan penjualan bahan makanan basah seperti daging, sayuran dan buah di area los pada lantai semi-basement dan penempatan penjualan makanan siap-santap di lantai paling atas dalam bentuk area food court. Namun belum terdapat pemisahan komoditas yang lebih jelas pada kios sehingga tetap ditemukan penjual roti di lantai mezzannine yang bersebelahan dengan penjual material dan peralatan pertukangan. Hal ini berpotensi untuk menimbulkan ketidaknyamanan dan juga masalah keselamatan bagi pengunjung.

Pasar Santa kini memiliki tipe dan ukuran ruang yang lebih beragam dibandingkan sebelum revitalisasi sehingga memberikan pilihan yang sesuai dengan kebutuhan pedagang dan penyedia jasa di sana. Saat ini kios telah dilengkapi dengan rolling door sehingga tindak kriminalitas dapat dicegah ketika pasar sedang tidak beroperasi. Material bangunan dan konstruksi yang digunakan pada ruang dagang pada saat ini juga telah memenuhi ketentuan Pemerintah RI dengan digunakannya material penutup yang tahan karat berupa keramik.

Dalam hal pengakomodasian fungsi penyimpanan barang tetap tidak ada perubahan kondisi pada saat sebelum dan sesudah revitalisasi dilakukan, yakni tidak terdapat gudang khusus yang terpisah ataupun tergabung di dalam kios dan los. Hal ini memicu adanya penggunaan kios dan los yang kosong atau non-aktif sebagai gudang yang menyebabkan area sekitarnya menjadi sepi yang kemudian berpotensi untuk menyebabkan permasalahan terkait keamanan.

Setelah revitalisasi dilakukan, terdapat upaya pembatasan yang lebih jelas antara tempat pembuangan sampah sementara (TPS) dengan area lain pada tapak Pasar Santa. Pintu masuk ke dalam bangunan pun dijauhkan dari TPS sehingga kini persyaratan dari ketentuan Pemerintah RI terkait dengan jarak antara tempat perdagangan dengan TPS sejauh minimal $10 \mathrm{~m}$ telah terpenuhi. Akses ke TPS juga terpisah dari akses ke tapak Pasar secara umum.

Untuk akses masuk dan keluar, alur sirkulasi dan area parkir kendaraan bermotor telah dipisahkan untuk mobil dan motor. Namun belum ada perbedaan antara sirkulasi dan area parkir mobil pribadi dan kendaraan distribusi barang.

Dalam hal ruang sirkulasi di antara kios dan los, persyaratan terkait lebar koridor, selasar terbuka serta tangga dan ramp telah terpenuhi, yakni $1,2-1,8 \mathrm{~m}$. Walau tetap ditemukan pedagang yang 
memajang komoditasnya di jalur sirkulasi, namun hal tersebut tidak mengurangi ruang sirkulasi menjadi lebih kecil dari 1,2 $\mathrm{m}$ seperti sebelum revitalisasi.

Ruang pendukung lainnya seperti ruang pengelola dan ruang ibadah difasilitasi di lantai yang terpisah yakni pada level sejajar atap bangunan pasar secara keseluruhan sehingga lebih terasa leluasa dan dapat menampung lebih banyak orang untuk berbagai kegiatan yang berbeda. Dalam hal sanitasi, persyaratan terkait jumlah sanitasi minimal telah terpenuhi dimana untuk 50 - 100 orang pengguna harus terdapat 3 kamar mandi dan 3 WC dengan penambahan 1 kamar mandi dan 1 WC untuk setiap penambahan pengguna sebanyak 40-100 orang. Adapun jumlah total sanitasi pada Pasar Santa adalah 12 wastafel, 24 urinal, 6 WC, dan 6 kamar mandi untuk pria sedangkan untuk wanita adalah 12 wastafel, 12 WC dan 6 kamar mandi. Jumlah ini menunjukkan maksimal penggunaan toilet setidaknya oleh 600 orang pria dan 600 orang wanita.

\section{KESIMPULAN}

Pasar tradisional merupakan sarana pemenuhan kebutuhan terutama bahan pokok bagi masyarakat di sekitarnya. Pengakomodasian ruang untuk fungsi pasar agar dapat berjalan dengan lancar dan dapat memberikan rasa aman, nyaman dan tidak menimbulkan masalah kesehatan bagi penggunanya merupakan hal yang penting. Oleh karenanya, hal ini diatur dalam berbagai ketentuan Pemerintah seperti yang dirujuk dalam penelitian ini. Dalam melihat kesesuaiannya terhadap peraturan dan standar yang berlaku, sangat penting untuk dilakukan pengamatan Pasar Santa sejak pasar tersebut bergabung dengan PD Pasa Jaya sampai dengan masa operasionalnya kini. Pasar Santa dalam masa operasionalnya sekarang dilakukan telah memenuhi mayoritas dari ketentuanketentuan tersebut dalam aspek ruang akomodasi fungsi pasar. Dengan demikian, besar harapannya agar pemenuhan ketentuan-ketentuan tersebut dapat dipelihara dan ditingkatkan, misalnya dengan pengakomodasian fungsi gudang secara khusus, agar seluruh kegiatan yang ada di Pasar Santa dapat berjalan lebih lancar kedepannya.

\section{DAFTAR PUSTAKA}

Pemerintah Republik Indonesia. 2008. Keputusan Menteri Kesehatan Republik Indonesia No. 519/Menkes/SK/IV/2008. Jakarta: Kementerian Kesehatan Republik Indonesia

Pemerintah Republik Indonesia. 2013. Peraturan Menteri Perdagangan Republik Indonesia No. 70/M-DAG/PER/12/2013. Jakarta: Kementerian Perdagangan Republik Indonesia

Pemerintah Republik Indonesia. 2013. Peraturan Menteri Perdagangan Republik Indonesia No. 37/M-DAG/PER/5/2017. Jakarta: Kementerian Perdagangan Republik Indonesia

Badan Standarisasi Nasional. 2015. Standar Nasional Indonesia no. 8152 - 2015 tentang Pasar Rakyat. Jakarta: Badan Standarisasi Nasional

PD Pasar Jaya. 2014. Menyulap Pasar Santa menjadi Tempat Nongkrong Anak Muda. Diakses bulan April 2021. Dari: http://www.pasarjaya.co.id/berita/detail/ Menyulap-Pasar-Santa-Jadi-Tempat-

Nongkrong-Anak-Muda

Rahardjo, A. 2005. Spending Life at the Market: A Conceptual Design for Santa Market in Jakarta, Indonesia. Calgary: University of Calgary Press 